\title{
ARTÍCULOS
}

\section{Efecto del subcultivo sucesivo sobre la caulogénesis adventicia de Eucalyptus globulus}

\author{
Effect of successive subculture on adventitious caulogenesis \\ of Eucalyptus globulus
}

\author{
Cristian Gómez ${ }^{a, b *}$, Darcy Ríos ${ }^{a, b}$ y Manuel Sánchez-Olate ${ }^{a, b}$ \\ *Autor de correspondencia: a Universidad de Concepción, Centro de Biotecnología, Laboratorio de Cultivo \\ de Tejidos Vegetales, Concepción, Chile, Casilla 160-C, Tel.: 56-41-207241, crigomez@udec.cl \\ bUniversidad de Concepción, Facultad de Ciencias Forestales, Concepción, Chile.
}

\begin{abstract}
SUMMARY
The effect of successive subcultures on the microshoots production from organogenic lines of cigotic material of Eucalyptus globulus was studied. Nodal segments were subcultured every 50 days on proliferation medium (MS $+4.4 \mu \mathrm{M}$ BAP $+0.05 \mu \mathrm{M}$ ANA) and the microshoots per explant were counted. The results indicated a decrease in the quantity of microshoots from the $3^{\text {rd }}$ to the $6^{\text {th }}$ subculture (1.58 to 0.18 microshoots per explant), accompanied by a high density of mass proliferation. This effect was reverted by maintaining the mass proliferation in a free hormone MS medium for 30 days and later transferring it to a shoots proliferation medium. The proliferation index increased from 0.18 , in the $6^{\text {th }}$ subculture, and up to 1.03 shoots per explant in the $7^{\text {th }}$ subculture. The results indicated that maintaining the explants in cytokinins and auxins presence during successive subcultures induces a decrease in the caulogenic competition and consequently, a smaller microshoots production. Transferring the explants to free hormones medium helps to recover the lost or diminished competition, allowing an increase in the microshoots production with exogenous cytokinins and auxins.
\end{abstract}

Key words: successive subcultures, adventitious caulogenesis, microshoots, Eucalyptus globulus.

\section{RESUMEN}

Se estudió el efecto de subcultivos sucesivos sobre la producción de microtallos desde líneas organogénicas de material cigótico de Eucalyptus globulus. Cada 50 días fueron subcultivados segmentos nodales en medio de proliferación (MS $+4,4 \mu \mathrm{M}$ BAP + $0,05 \mu \mathrm{M}$ ANA) y se contabilizó el número de microtallos por explanto. Los resultados indicaron una disminución en la cantidad de microtallos desde el $3^{\circ}$ al $6^{\circ}$ subcultivo (de 1,58 a 0,18 microtallos por explanto), que fue acompañada por una compactación general de los macizos de proliferación. Este efecto se revirtió manteniendo los macizos en un medio MS libre de hormonas por 30 días y posterior transferencia a medios de proliferación de brotes, con lo cual el índice de proliferación aumentó desde 0,18 , en el $6^{\circ}$ subcultivo, hasta 1,03 brotes por explanto en el $7^{\circ}$ subcultivo. Los resultados indicaron que mantener los explantos durante subcultivos sucesivos en presencia de citoquininas y auxinas induce una disminución en la competencia caulogénica y por consiguiente, una menor producción de microtallos. El repicar el material a un medio libre de hormonas ayuda a recuperar la competencia perdida o disminuida, permitiendo el aumento en la producción de microtallos con citoquininas y auxinas exógenas.

Palabras clave: subcultivos sucesivos, caulogénesis adventicia, microtallos, Eucalyptus globulus.

\section{INTRODUCCIÓN}

Los principales problemas que se detectan en el proceso de micropropagación del eucalipto, aparte del efecto edad, están relacionados con la respuesta específica del genotipo, tipo de explanto, escasa eficiencia de la inducción, multiplicación y elongación de tallos, par- deamiento de los explantos usados, presencia de contaminación fúngica y/o bacteriana y escasa tasa de rizogénesis. Además, los trabajos publicados se enfocan principalmente a la búsqueda de combinaciones hormonales y medios nutritivos óptimos para lograr una alta producción de brotes o raíces (Ahuja 1993, Tapia et al. 1998). 
Con respecto a los efectos del subcultivo sucesivo sobre la caulogénesis adventicia, sólo existen reportes para Eucalyptus nitens Maiden desde material adulto revigorizado y no a partir de cadenas proliferativas desde material cigótico (Tapia y González 2000). Según estos estudios, la caulogénesis adventicia decrece desde el $8^{\circ}$ subcultivo en un medio $\mathrm{MS}^{1}$ suplementado con ácido naftalenacético (ANA) y benciladenina (BA), existiendo una marcada respuesta clonal dependiendo de la edad del material.

Este tema ya ha sido abordado en otras especies leñosas y los resultados indican que la formación de brotes adventicios inicialmente aumenta con el número de subcultivos, con lo cual se produce un efecto revigorizante sobre los explantos. Posteriormente, esta proliferación comienza a decaer desde un determinado número de subcultivos (Sánchez 1996, Fernández-Lorenzo et al. 2001, Avilés 2003), no especificándose el efecto fisiológico de los reguladores de crecimiento exógenos sobre los tejidos involucrados en la inducción de nuevos centros meristemáticos

La carencia de reportes que analicen este tema a partir de material cigótico en Eucalyptus globulus Labill sustenta el desarrollo de este trabajo cuando se quieren establecer líneas organogénicas desde germoplasma proveniente de huertos semilleros de polinización controlada. Por lo tanto, el objetivo de esta investigación es analizar el efecto del subcultivo sucesivo in vitro sobre la producción de microtallos de E. globulus.

\section{MÉTODOS}

Material vegetal. Se utilizaron semillas de E. globulus procedentes de Cauquenes (35 $47^{\circ}$ ' S, 72 $5^{\circ}$ ' O; cosecha temporada 98/99) donadas por el Instituto Forestal. Las semillas se desinfectaron con etanol al $70 \%(\mathrm{v} / \mathrm{v})$ por tres minutos; lavado en agua destilada estéril por un minuto; hipoclorito de sodio comercial al $50 \%$ (v/v) por $15 \mathrm{minu}-$ tos y finalmente 3 lavados con agua destilada estéril de 1,2 y 3 minutos de duración.

Germinación. Una vez realizada la asepsia, las semillas se depositaron en frascos de vidrio con $20 \mathrm{ml}$ de medio MS (Murashige y Skoog 1962) libre de hormonas y con los macronutrientes diluidos en un $25 \%(\mathrm{p} / \mathrm{v})$, durante 21 días en oscuridad y a $24^{\circ} \mathrm{C} \pm 2{ }^{\circ} \mathrm{C}$. Posteriormente fueron transferidas a condiciones de fotoperíodo de $16 \mathrm{~h}$ luz y $25^{\circ} \mathrm{C} \pm 2{ }^{\circ} \mathrm{C}$, hasta que formaron dos pares de hojas y alcanzaron como promedio $5 \mathrm{~cm}$ de longitud.

1 Abreviaciones: BAP - bencilaminopurina; ANA - ácido naftalenacético; MS - Murashige y Skoog, solución mineral (Murashige y Skoog 1962).
Luego se les escindió la raíz y los tallos fueron establecidos en medios de proliferación.

Proliferación de brotes adventicios. Se inocularon cuatro segmentos nodales de $2 \mathrm{~cm}$ de longitud en frascos de cultivo de $9,5 \mathrm{~cm}$ de alto por $6 \mathrm{~cm}$ de diámetro, conteniendo $20 \mathrm{ml}$ de medio de proliferación MS suplementado con BAP $(4,4 \mu \mathrm{M})$ y ANA $(0,05 \mu \mathrm{M})$. Cada 50 días se subcultivaron todos los microtallos de $0,5 \mathrm{~cm}$ de longitud, estableciendo nuevamente 4 segmentos nodales en los medios de proliferación. Para el análisis cuantitativo, se contabilizó el número de microtallos de 0,5 $\mathrm{cm}$ de longitud obtenidos desde los subcultivos $1^{\circ}$ al $7^{\circ}$ y además se observaron las diferencias morfológicas de las hojas con respecto a su tamaño y el largo de los entrenudos de los brotes inducidos. Cuando fue imposible subcultivar más microtallos, los macizos de proliferación se establecieron en medio MS sin hormonas durante 30 días y se repicaron posteriormente al medio de proliferación original durante 50 días, con el objeto de cuantificar el efecto de la carencia en la aplicación de reguladores exógenos.

Análisis estadístico. Para los análisis estadísticos se aplicó el software Statistica 6.0. Los tratamientos correspondieron al número de subcultivo. La unidad experimental estuvo conformada por un recipiente de vidrio con cuatro explantos inoculados en medio de proliferación. Cada unidad experimental se repitió 20 veces. El ensayo se analizó mediante un diseño completamente al azar. Finalmente se realizó un ANDEVA no paramétrico mediante la prueba de Kruskal-Wallis para muestras no balanceadas, evaluando como variable dependiente el número de microtallos por explanto en cada subcultivo. Cuando se detectaron diferencias significativas entre tratamientos, éstas se identificaron mediante comparaciones múltiples aplicando la prueba de Dunn a un nivel de significancia del $5 \%$.

\section{RESULTADOS}

Los resultados indicaron una disminución del número de microtallos por explanto con el aumento en el número de subcultivos. Para los tres primeros subcultivos no se encontraron diferencias significativas entre ellos, pero sí entre el $3^{\circ}$ (correspondiente al valor más alto) y el $5^{\circ}$ y $6^{\circ}$ subcultivo, donde se obtuvieron los valores más bajos (figura 1). A medida que aumentó el número de subcultivos, los macizos de proliferación presentaron un aspecto compacto, con formación de callo basal e hiperhidratación de hojas. Además, la longitud de los entrenudos fue menor, razón que influyó directamente en la producción de microtallos al final del $5^{\circ}$ y $6^{\circ}$ subcultivo. 


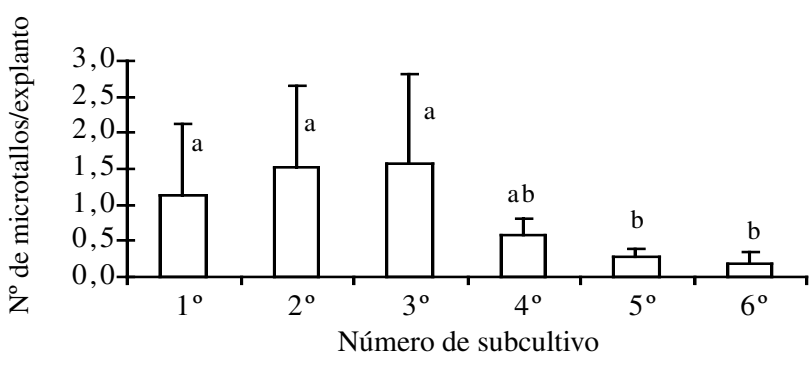

Figura 1. Número de microtallos por explanto producidos desde el $1^{\circ}$ al $6^{\circ}$ subcultivo. Sobre las barras se indica la desviación estándar de los datos. Letras distintas indican diferencias significativas $(P<0,05)$.

Microshoots number per explant formed from the $1^{\text {st }}$ to the $6^{\text {th }}$ subculture. Standard deviation is indicated on the bars. Different letters indicate significant differences $(P<0.05)$.
Comparando la producción al $6^{\circ}$ subcultivo en dos condiciones, la primera manteniendo los explantos en medio de proliferación y la otra manteniendo brotes que procedían del $5^{\circ}$ subcultivo durante 30 días en medio base (MS sin hormonas), y después 50 días en medio de proliferación, se obtuvo un aumento significativo desde 0,18 a 0,99 microtallos/explanto (figura 2 ).

Al realizar un $7^{\circ}$ subcultivo, manteniendo los explantos durante 30 días en medio base, se obtuvo un aumento en la caulogénesis que alcanzó hasta 1,03 microtallos/ explanto, sin diferir significativamente del subcultivo $6^{\circ}$ (figura 3). Con esta modificación, se facilitó la elongación de los brotes, mejorando la calidad de los segmentos nodales obtenidos. Además se observó un aumento en la superficie foliar y una disminución de la hiperhidricidad de las hojas.

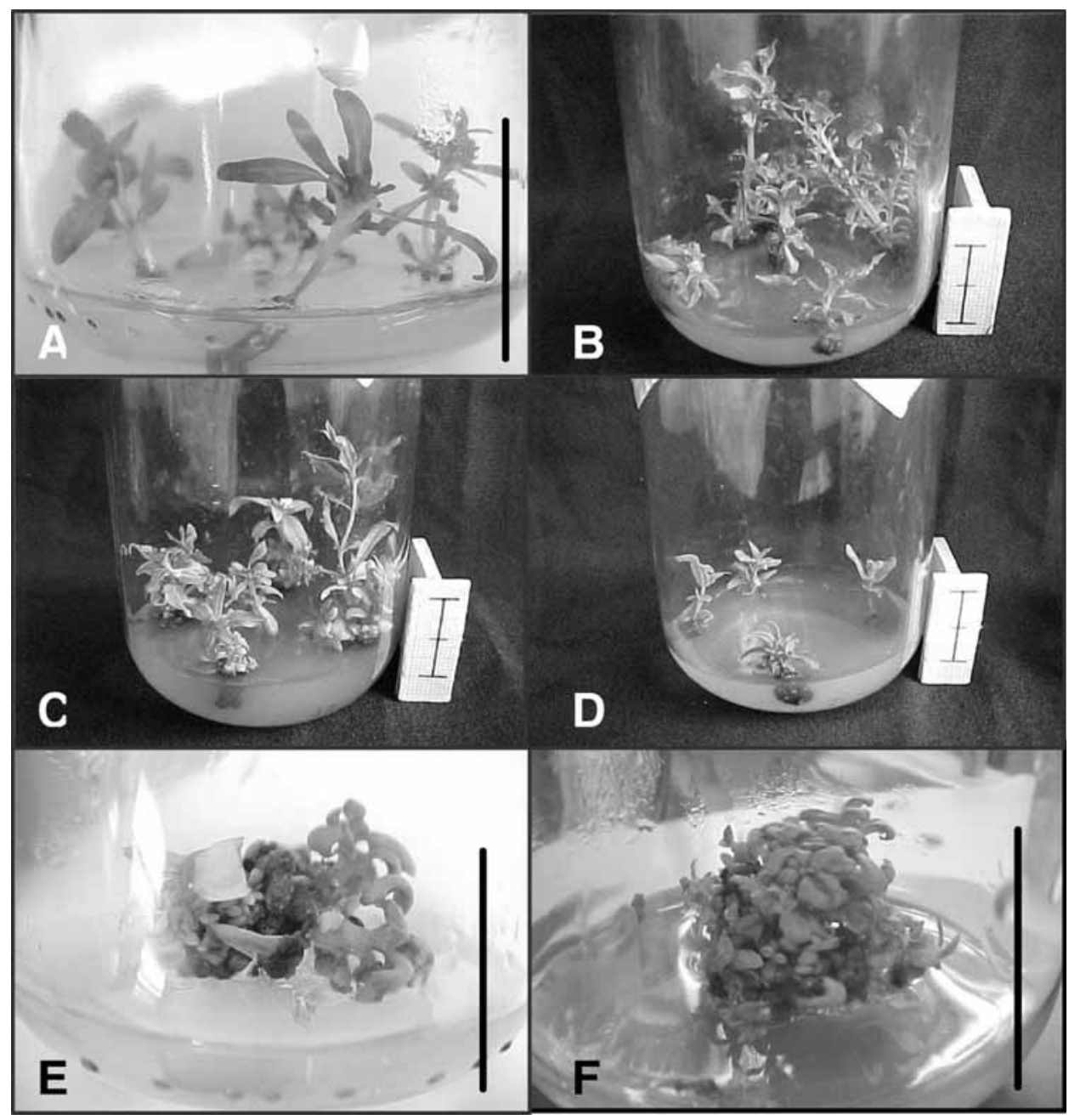

Figura 2. Aspectos macromorfológicos de la caulogénesis adventicia en función de los diferentes subcultivos. A) Brotes del $1^{\circ}$ subcultivo. B) Brotes del $2^{\circ}$ subcultivo. C) Brotes del $3^{\circ}$ subcultivo. D) Brotes del $4^{\circ}$ subcultivo. E) Brotes del $5^{\circ}$ subcultivo. F) Brotes del $6^{\circ}$ subcultivo. Barras $=2 \mathrm{~cm}$.

Macromorphological aspects of adventitious caulogenesis in function of the different subcultures. A) Shoots from the first subculture. B) Shoots from the second subculture. C) Shoots from the third subculture. D) Shoots from the fourth subculture. E) Shoots from the fifth subculture. F) Shoots from the sixth subculture. Bars $=2 \mathrm{~cm}$. 

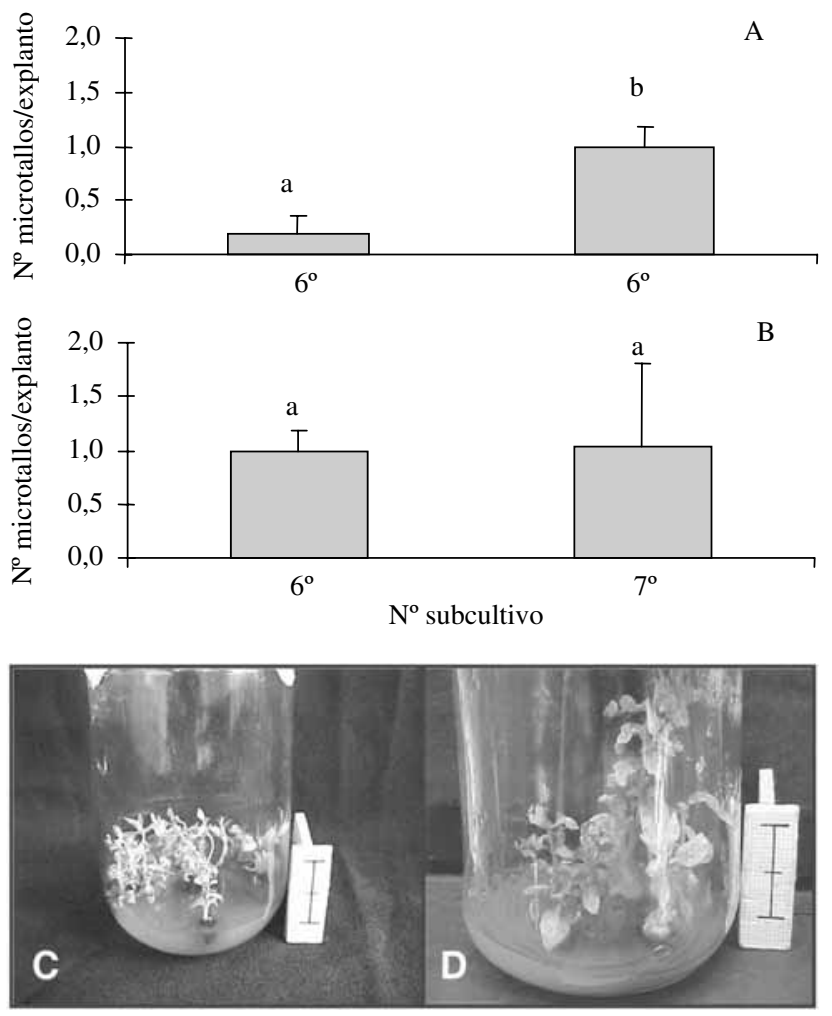

Figura 3. A) Número de microtallos por explanto producidos en el $6^{\circ}$ subcultivo, comparando la producción obtenida desde el $5^{\circ}$ al $6^{\circ}$ subcultivo en medio de proliferación (izquierda) y desde el $5^{\circ}$ al $6^{\circ}$ subcultivo, manteniendo los explantos durante 30 días en medio base y 50 días en medio de proliferación (derecha). B) Número de microtallos por explanto producidos en el $6^{\circ}$ y $7^{\circ}$ subcultivo manteniendo los explantos en medio base y posteriormente en medio de proliferación. Sobre las barras se indica la desviación estándar de los datos. Letras distintas indican diferencias significativas $(P<0,05)$. C y D) Aspectos macromorfológicos de la caulogénesis adventicia después de mantener los explantos en medio base durante 30 días y posteriormente en medio de proliferación por 50 días. Brotes del $6^{\circ}$ subcultivo en (C) y brotes del $7^{\circ}$ subcultivo en (D). Barras $=2 \mathrm{~cm}$.

A) Number of microshoots per explant formed in the $6^{\text {th }}$ subculture, compared with the production obtained from the $5^{\text {th }}$ to the $6^{\text {th }}$ subculture in proliferation medium (left) and from the $5^{\text {th }}$ to the $6^{\text {th }}$ subculture; maintaining the explants during 30 days in basal medium and 50 days in proliferation medium (right). B) Number of microshoots per explant formed in the $6^{\text {th }}$ and $7^{\text {th }}$ subculture maintaining the explants on basal medium and later on proliferation medium. Standard deviation is indicated on the bars. Different letters indicate significant differences*. C) and D) Macromorphological aspects of the adventitious caulogenesis after maintaining the explants on basal medium during 30 days and later on proliferation medium for 50 days. Shoots from the $6^{\text {th }}$ subculture in (C) and shoots from the $7^{\text {th }}$ subculture in (D). Bars $=2 \mathrm{~cm}$.

\section{DISCUSIÓN}

Los resultados indican un efecto directo de la acción de los reguladores de crecimiento exógenos aplicados. Según Durand-Cresswell et al. (1982) y Ahuja (1993), el desencadenamiento de la caulogénesis in vitro depende de una relación óptima entre las concentraciones totales de citoquininas y de auxinas exógenas y endógenas. Sin embargo, la respuesta es muy variable dependiendo de la especie y del tipo de explanto utilizado. Sánchez (1996), en estudios de micropropagación de nogal a partir de embriones aislados, encuentra una respuesta similar, ya que el coeficiente de proliferación disminuyó con el aumento del tiempo que los explantos permanecen en cultivo $\left(7^{\circ}\right.$ y $12^{\circ}$ subcultivo). Esto pone de manifiesto un descenso en la capacidad morfogénica de los tejidos utilizados, lo que puede llevar a una menor respuesta a otros tratamientos efectuados, como por ejemplo, el proceso rizogénico. De esta manera, Avilés (2003), al estudiar el efecto de los subcultivos $7^{\circ}$ al $12^{\circ}$ sobre el enraizamiento de microtallos de castaño (Castanea sativa Mill.) de origen cigótico, encuentra que el número de subcultivos afecta la supervivencia de microtallos y el porcentaje de enraizamiento. De igual manera, Vieitez et al. (1985) en la regeneración in vitro de castaño, establecen un efecto de los reguladores de crecimiento sobre el aumento de la vitrificación y la disminución de brotes en cada subcultivo, lo que posteriormente afecta la supervivencia y el porcentaje de enraizamiento.

Como consecuencia del efecto acumulado de la exposición de los microtallos a estas condiciones durante la multiplicación, se produce una disminución de la supervivencia de los mismos durante el proceso de enraizamiento. En cambio, Fernández-Lorenzo et al. (2001) al estudiar la micropropagación de castaño, utilizando material adulto, también encuentran una disminución progresiva en la producción de microtallos, pero a partir del $2^{\circ}$ subcultivo. En E. globulus no se conocen estudios del efecto de los subcultivos sobre la proliferación de microtallos a partir de material embrionario. Tapia y González (2000) establecen una disminución de la proliferación de brotes adventicios in vitro de $E$. nitens adulto, a partir del $8^{\circ}$ subcultivo, indicando que existe una marcada respuesta clonal y que la magnitud y rapidez de las respuestas dependen de la edad del material inicial.

Para explicar esta declinación progresiva de la organogénesis es posible basarse en dos hechos ya estudiados. El primero establece que los cambios genéticos producidos en el cultivo in vitro, principalmente poliploidía y aneuploidía, afectarían la competencia organogénica de los explantos. El segundo, que no excluye al anterior, hace relación a un agotamiento fisiológico de los explantos debido a factores endógenos hormonales y tróficos (Sacristan y Melchers 1969, Wright y Northcote 1973).

Con respecto a la primera afirmación, Azmi et al. (1997), en un estudio de organogénesis in vitro desde hipocótilos de E. globulus, no encuentran evidencia de poliploidía en los regenerantes. Solamente constatan alteraciones fenotípicas en los nuevos brotes inducidos a través de los distintos subcultivos. Al parecer los resultados obtenidos se explican principalmente desde un punto 
de vista fisiológico. Según Muhitch y Fletcher (1985), las células, al envejecer en cultivo, aumentan la probabilidad de sintetizar productos nocivos para el crecimiento vegetal, por lo cual la tasa de proliferación disminuye a medida que el número de subcultivos aumenta. Esta segunda hipótesis también ha sido corroborada por Sánchez-Olate et al. (2002), al evaluar los contenidos endógenos de poliaminas en nogal, encontrando un descenso de poliaminas asociadas a la división celular (putrescina) $\mathrm{y}$ un aumento de aquellas asociadas al envejecimiento y maduración (espermina y espermidina), a medida que aumentaba el número de los subcultivos.

Según Trindade et al. (1990), la aplicación de citoquinina es muy importante para la cantidad y calidad de los brotes de E. globulus inducidos in vitro, ya que sin ella, se obtiene hasta un $75 \%$ de necrosis en los brotes inducidos después de un cierto número de subcultivos. Estos mismos autores indican que la aplicación de BAP en los mismos rangos de concentración que kinetina, produce mayor formación de brotes. Más aún, con BAP es posible obtener brotes más vigorosos, mientras que kinetina induce hojas deformes y pequeñas. Bajas concentraciones de $\operatorname{BAP}(0,4-1,1 \mu \mathrm{M})$ estimulan una rápida multiplicación de brotes, solamente en combinación con una alta concentración auxínica.

Se concluye que el mantener los explantos durante los diferentes subcultivos bajo la acción de los reguladores de crecimiento, origina una disminución en su capacidad caulogénica y por consiguiente una menor producción de microtallos en cada subcultivo. Al repicar el material a un medio libre de hormonas, se recupera la competencia perdida o disminuida, permitiendo aumentar nuevamente la producción de microtallos al aplicar citoquininas y auxinas exógenas. Además, manteniendo los explantos en medio libre de hormonas durante un tiempo, se favorece la elongación de los entrenudos, obteniendo una mayor cantidad de explantos para el siguiente subcultivo. De esta manera, la carencia hormonal exógena se puede utilizar como herramienta de control de la pérdida de vigor.

\section{REFERENCIAS}

Ahuja M. 1993. Biotechnology and clonal forestry. In Ahuja M y Libby W eds. Clonal Forestry I: genetics and biotechnology. Institute of Forest Genetics. Germany. p. 135-144.

Avilés F. 2003. Variación de la tasa de enraizamiento asociada al número de subcultivo y diámetro de microtallo de Castanea sativa Mill. Tesis Ingeniero Forestal. Concep- ción, Chile. Facultad de Ciencias Forestales, Universidad de Concepción. 42 p.

Azmi A, M Noin, P Landré, M Prouteau, A Boudet, D. Chriqui. 1997. High frequency plant regeneration from $\mathrm{Eu}$ calyptus globulus Labill. Hypocotils: Ontogenesis and ploidy level of the regenerants. Plant Cell, Tissue and Organ Culture 51: 9-16.

Durand-Cresswell R, M Boulay, A Franclet. 1982. Vegetative propagation of Eucalyptus. In Bonga J, Durzan D eds. Tissue Culture in Forestry. Boston, London. p. 150-181.

Fernández-Lorenzo J, S Rodríguez, M Veiga. 2001. Micropropagación de dos cultivares de fruto de Castanea sativa Mill. In III Congreso Forestal Español. Granada 25-28 septiembre. Dpto. de Producción Vegetal. Escola Politécnica Superior de Lugo. Universidad de Santiago de Compostela. Campus Universitario s/n. 27002 Lugo.

Muhitch M, J Fletcher. 1985. Influence of culture age and Spd treatment on the accumulation of phenolic compounds in suspension cultures. Plant Physiology 78: 25-28.

Murashige T, F Skoog. 1962. A revised medium for rapid growth and bioassays with tobacco tissue cultures. Physiol. Plant 15: 473-497.

Sacristan M, G Melchers. 1969. The caryological analysis of plants regenerated from tumorous and other callus cultures of tobacco. Molecular and General Genetics 105(4): 317-333.

Sánchez M. 1996. Bases macromorfológicas y moleculares de la micropropagación de Nogal (Juglans regia L. cv. Serr). Tesis Doctoral. Oviedo, España. Universidad de Oviedo. $202 \mathrm{p}$.

Sánchez-Olate M, D Ríos, M Revilla, R Rodríguez. 2002. Participación de poliaminas endógenas en el desarrollo de injertos y brotes epicórmicos de nogal. Agro-Ciencia 17(2): 215-219.

Tapia M, M Paredes, P González, P Videla, R Avilés. 1998. Avances en Micropropagación de Eucalyptus nitens. In XI Silvotecna. Biotecnologías Aplicadas a la Silvicultura de Especies Forestales de Rápido Crecimiento. Corma VIII Región del Bío-Bío. Concepción, Chile.

Tapia M, P González. 2000. Micropropagación de Eucalyptus nitens. In Seminario Micropropagación y caracterización genética de Eucalyptus nitens (Maiden). INIA ed. Parque Jorge Alessandri, Concepción.

Trindade H, J Ferreira, M Pais, R Aloni. 1990. The role of citokinin and auxin in rapid multiplication of shoots of Eucalyptus globulus grown in vitro. Australian Forestry 53(3): 221-223.

Vieitez A, A Ballester, M San José, E Vieitez. 1985. Anatomical and chemical studies of vitrified shoots of chestnut regenerated in vitro. Physiologia Plantarum 65: 177-184.

Wright K, D Northcote. 1973. Differences of ploidy and degree of intercellular contact in differentiating and non differentiating sycamore calluses. Journal Cell Science 12: $37-53$. 